\title{
Geologia
}

\section{Geoquímica de Gnaisses do Arco Magmático de Goiás na Região Sul do Estado de Goiás}

\author{
Guillermo Rafael Beltran Navarro (grbnavarro@yahoo.com.br) e Antenor Zanardo \\ Departamento de Petrologia e Metalogenia - Instituto de Geociências e Ciências Exatas - UNESP \\ Av. 24-A 1.515, CP 178, CEP 13506-900, Rio Claro, SP, BRA
}

Recebido em 02 de março de 2006; aceito em 30 de outubro de 2006

Palavras-chave: Faixa Brasília, Arco Magmático de Goiás, gnaisses, geoquímica.

\section{RESUMO}

Gnaisses graníticos a trondhjemíticos da região de Pontalina, sul do estado de Goiás, mostram composição cálcica a cálcio-alcalina, metaluminosa a peraluminosa. Apresentam baixos teores em álcalis, enriquecimento em Ba, Sr, K, Rb em relação ao Nb, Y, Zr e ETR e anomalias negativas de Nb e Ti, semelhantes à composição química de magmas gerados em ambientes de arcos magmáticos. Foram anteriormente interpretados como parte do embasamento da Faixa Brasília e atribuídos ao Arqueano e Paleoproterozóico, porém novos dados isotópicos Sm - Nd sugerem que estas rochas são neoproterozóicas ( $\mathrm{T}_{\mathrm{DM}}=0,9$ a 1,2 Ga) e os dados geoquímicos indicam que são semelhantes a rochas de outras regiões pertencentes ao Arco Magmático de Goiás.

Keywords: Brasília Belt, Goiás Magmatic Arc, gneisses, geochemistry.

\section{ABSTRACT}

Granitic to trondhjemitic gneisses from the Pontalina region in the southern part of Goiás State, Central Brazil, have calcic to calc-alkaline, metaluminous to peraluminous compositions. They have low concentrations of alkaline elements, and are enriched in $\mathrm{Ba}, \mathrm{Sr}, \mathrm{K}, \mathrm{Rb}$ in relation to $\mathrm{Nb}, \mathrm{Y}, \mathrm{Zr}$ and $\mathrm{REE}$, and have negative anomalies of $\mathrm{Nb}$ and Ti, features which are similar to those of magmas generated in magmatic arc environments. Those rocks were previously interpreted as part of the basement of the Brasília Belt, attributed to the Archean to Paleoproterozoic, but new Sm - Nd isotopic data indicate a neoproterozoic age $\left(\mathrm{T}_{\mathrm{DM}}=0,9 \mathrm{a} 1,2 \mathrm{Ga}\right)$, and the preliminary geochemical data reveal compositions similar to the gneisses of the other regions belonging to the Goiás Magmatic Arc. 


\section{INTRODUÇÃO}

Na porção oeste-sudoeste do estado de Goiás ocorre uma extensa faixa de gnaisses, com orientação geral N-S, anteriormente relacionados ao embasamento da Faixa Brasília e atribuídos a idades arqueanas a paleoproterozóicas. Trabalhos elaborados ao longo da última década incorporaram novos dados isotópicos e geocronológicos e mostram que grande parte destes gnaisses é resultante de magmas juvenis neoproterozóicos, correspondentes a antigos arcos de ilhas, que são agrupados sob a denominação de Arco Magmático de Goiás (Fuck et al., 1994) (Figura 1).

As regiões-tipo de exposição e melhor estudadas afloram na porção oeste de Goiás, região de Arenópolis-Piranhas, e noroeste, região de Mara Rosa-Porangatu. Os dados geocronológicos, geoquímicos e isotópicos disponíveis sugerem que o Arco Magmático de Goiás é resultado de um sistema de arcos de ilhas intraoceânicos, caracterizados por tonalitos a dioritos cálcio-alcalinos, e vulcânicas associadas, formados por dois eventos de acreção crustal, um entre $\sim 900$ e $\sim 800$ Ma e outro entre $\sim 670$ a $\sim 600$ Ma (Pimentel et al., 2004; Laux et al., 2005). Dados isotópicos e geocronológicos apresentados por Rodrigues et al. (1999), Pimentel et al. (2000) e Navarro et al. (2004) estendem a ocorrência de rochas juvenis associadas ao Arco Magmático de Goiás até a região de Pontalina-Burití Alegre (Figura 1).

Na região de Pontalina os terrenos gnáissicos associados ao Arco Magmático de Goiás são agrupados sob a denominação informal de Terrenos Gnáissico-Metassedimentares, que é subdividido em duas unidades geológicas: Unidade Gnáissica e Unidade Metassedimentar. A Unidade Gnáissica [Conjunto Migmatítico (Araújo et al., 1980), Complexo Granitóide Gnáissico (Lacerda Filho, 1995)] é limitada a leste e a norte pelo Grupo Araxá e a oeste pela Unidade Metassedimentar (Figura 1). Consiste em uma faixa de gnaisses variados que incluem muscovita gnaisse, biotitamuscovita gnaisse, hornblenda gnaisse, hornblenda-biotita ganisse porfiróides ou não, geralmente quartzosos e ricos em epidoto. Apresentam grau variado de milonitização com predomínio de termos com duas micas. São freqüentes intercalações de anfibolito, anfibólio xisto e granada anfibolito, de filiação toleítica e metassedimentares como muscovita xisto, muscovita-quartzo xisto. Mais raramente ocorrem serpentinito, talco xisto e clorita xisto associadas.

A Unidade Metassedimentar [Conjunto Migmatítico (Araújo et al., 1980) e parte da Seqüência Metavulcanossedimentar Anicuns-Itaberaí (Lacerda Filho, 1995)] é constituída por rochas metassedimentares pelíticas a psamopelíticas (muscovita xisto, muscovita quartzo xisto, quartzito, quartzito ferruginoso etc.) intercalados por gnaisses quartzosos (muscovita gnaisse, biotita-muscovita gnaisse, geralmente, com forte muscovitização e ricos em epidoto), metamáficas menos freqüentes que na unidade anterior, e prováveis metavulcânicas félsicas a intermediárias.

Os gnaisses são bandados, localmente porfiroblásticos ou porfiroclásticos, com grau variado de milonitização e granulação, de composição variável de granito a tonalito, com predomínio de granodioritos e tonalitos.

Rochas com características plutônicas afloram na região de Morrinhos, junto ao contato com o Grupo Araxá e a noroeste de Pontalina. São gnaisses granodioríticos a tonalíticos, homogêneos, representados por biotitahornblenda gnaisse e biotita gnaisse de granulação grossa a média, blastoporfiríticos, com xenólitos de metamáficas e metaultramáficas intercalados.

A porção central da área é constituída principalmente por biotita/muscovita gnaisses mais quartzosos, com estrutura xistosa e textura granoblástica a lepidoblástica, bandados, homogêneos, finos a médios, com lentes de rochas metamáficas e metassedimentares.

Estudos geoquímicos de rochas metamáficas associadas a estes gnaisses mostram que estas são compostas por basaltos subalcalinos e basaltos andesíticos, de afinidade toleítica subalcalina a alcalina, com características geoquímicas semelhantes aos basaltos oceânicos, principalmente do tipo E-MORB, com contribuições de basaltos de arco (Navarro et al., 2005).

As paragêneses minerais de ambas unidades são compatíveis com auge metamórfico na fácies anfibolito, sob temperatura mínima da ordem de $600^{\circ} \mathrm{C}$, e regime de pressão compatível ou superior ao barroviano. Relações texturais e microestruturais indicam que as associações minerais foram geradas no estágio inicial do desenvolvimento da foliação principal (Sn), ou mesmo antes.

Uma segunda assembléia mineral caracterizada por associações retrometamórficas constituídas por clorita, epidoto, albita, muscovita, sericita, evidencia variação das condições metamórficas da fácies anfibolito para a fácies xisto verde alto a médio.

A principal estrutura nestas rochas é uma foliação, normalmente paralela, a bandamento composicional. Esta foi denominada de foliação Sn e é caracterizada pela orientação de filossilicatos (muscovita, biotita, serpentina, talco, clorita etc.), grãos de quartzo alongados, prismas de epidoto, cristais de hornblenda orientados, trilhas de minerais opacos e agregados policristalinos lenticulares a fusiformes. Essa trama define uma xistosidade, com grau variável de desenvolvimento, feições blastomiloníticas de direção N-SE e baixo a médio mergulho para W. Localmente ocorre uma xistosidade bem desenvolvida denominada de foliação $\mathrm{Sn}-1$, paralela a um bandamento composicional milimétrico a métrico constituído por variações de porções lepidoblásticas e granoblásticas e pela intercalação, centimétrica a métrica de diferentes litotipos paralelos. Esta xistosidade Sn-1 é do- 


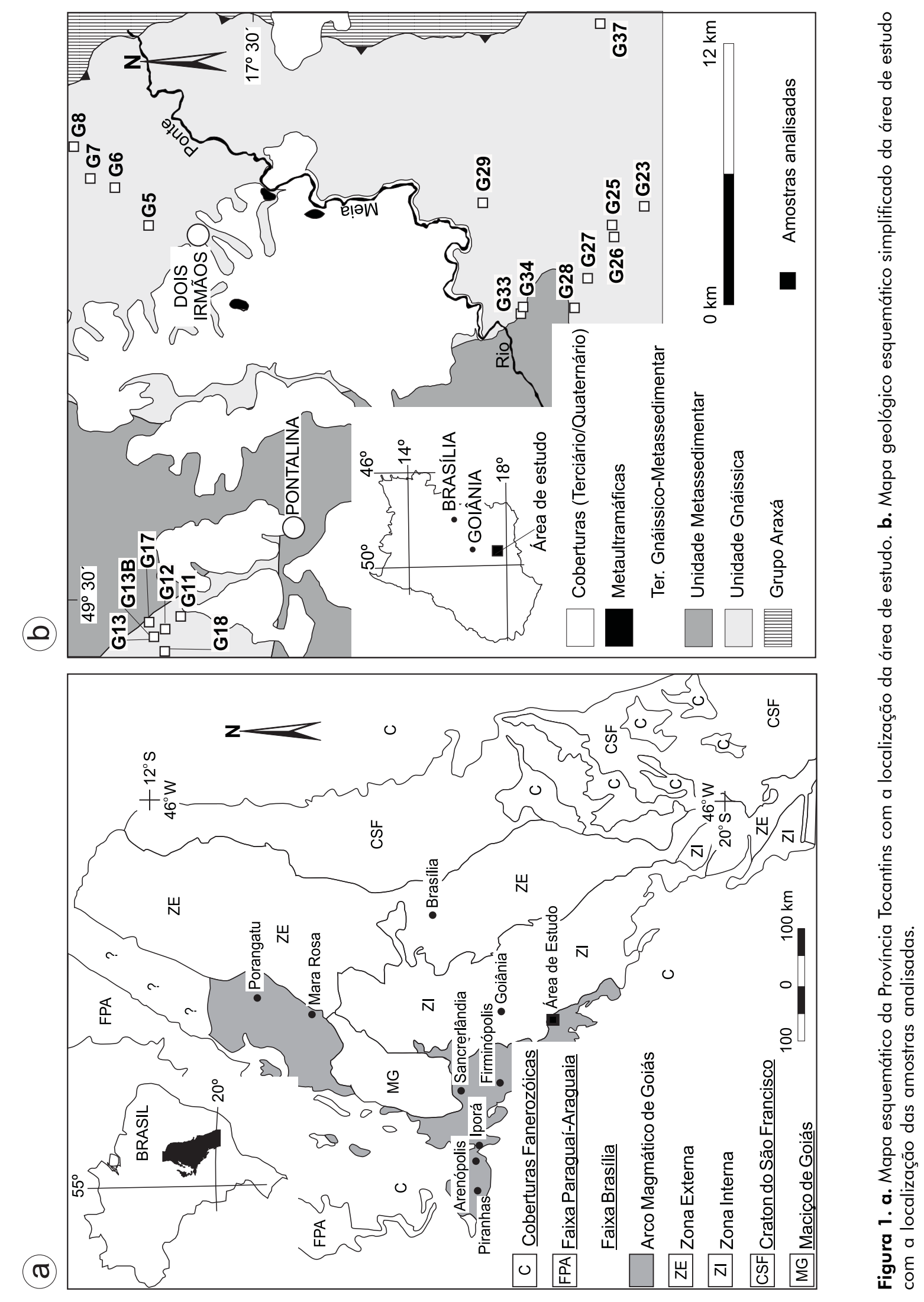


brada e transposta pela foliação principal (Sn).

Associado a Sn há uma lineação mineral e/ou de estiramento com direção E-W e baixo caimento para W. Os indicadores cinemáticos apontam sistematicamente transporte geral de $\mathrm{W}$ para $\mathrm{E}$.

\section{GEOQUÍMICA DOS GNAISSES}

Foram selecionadas 19 amostras de gnaisses da Unidade Gnáissica para estudos litogeoquímicos de elementos maiores $\left(\mathrm{SiO}_{2}, \mathrm{TiO}_{2}, \mathrm{Al}_{2} \mathrm{O}_{3}, \mathrm{Fe}_{2} \mathrm{O}_{3 \mathrm{~T}}, \mathrm{MnO}, \mathrm{MgO}, \mathrm{CaO}, \mathrm{Na}_{2} \mathrm{O}, \mathrm{K}_{2} \mathrm{O}\right.$ e $\mathrm{P}_{2} \mathrm{O}_{5}$ ) e traços ( $\mathrm{Ba}, \mathrm{Cr}, \mathrm{Cu}, \mathrm{Nb}, \mathrm{Ni}, \mathrm{Rb}, \mathrm{Sr}, \mathrm{Y}$ e $\mathrm{Zr}$ ) pelo método de Fluorescência de Raios X (FRX). Em sete amostras também foram obtidos os teores dos elementos terras raras ( $\mathrm{La}, \mathrm{Ce}$, Nd, Sm, Eu, Gd, Dy, Er, Yb e Lu) pelo método ICP-AES. As análises químicas foram feitas no Laboratório de Geoquímica (Labogeo) do Departamento de Petrologia e Metalogenia (DPM) do Instituto de Geociências e Ciências Exatas (IGCE) UNESP/Rio Claro. O tratamento dos dados geoquímicos e a construção de diagramas foram realizados com emprego do programa MINPET versão 2.02 (Richard, 1995).

A abertura química de amostras para análise isotópica Sm-Nd foi feita no Laboratório de Geoquímica Isotópica da UNESP/Rio Claro. A separação do Rb e Sr dos ETRs dos outros constituintes das amostras foi feita em colunas primárias (condicionada com $20 \mathrm{ml}$ de $\mathrm{HCl}$ de 2,5 N) carregadas com resina de troca catiônica BIO-RAD AG50W-X8AG50WX8 (200 - 400 mesh). Após várias etapas de lixiviação com $\mathrm{HCl} 2,5 \mathrm{~N}$, a coleta dos ETRs nessas colunas foi realizada com HCl 6N em savillex de teflon. A separação do Sm e do Nd dos demais elementos terras raras foi realizada em colunas secundárias (condicionadas com $\mathrm{HCl}$ 0,18 N) carregada com resina do tipo LN SPEC (resina líquida HDEHP-ácido di-etilhexil fosfórico) impregnada em pó de teflon de 200 400 mesh. Após várias etapas de lixiviação com $\mathrm{HCl}$ 0,18 N, para retirada dos demais elementos terras raras, coleta-se o Nd com HCl 0,18 N e o Sm com HCl 0,5 N em savillex e teflon (Hackspacher et al., 2004). Depois de secas em placa aquecedora as amostras foram analisadas em Espectrômetro de Massa por ionização termal (TIMS) da marca Finningan MAT-262 multicoletor do Laboratório de Geocronologia da Universidade de Brasília.

Os resultados mostram que os gnaisses da região de Pontalina apresentam grande variação no conteúdo de elementos maiores $\left(\mathrm{SiO}_{2}-63\right.$ a 81\%, $\mathrm{TiO}_{2}-0,20$ a 1,06\%, $\mathrm{Al}_{2} \mathrm{O}_{3}$ - 11,44 a 17,81\%, $\mathrm{Fe}_{2} \mathrm{O}_{3 \mathrm{~T}}-1,50$ a 6,32\%, $\mathrm{MnO}-0,03$ a 0,11\%, $\mathrm{MgO}-0,12$ a 2,42, $\mathrm{CaO}-0,47$ a 4,69\%; $\mathrm{Na}_{2} \mathrm{O}-1,70$ a 4,92\%, $\mathrm{K}_{2} \mathrm{O}-2,91$ a $4,15 \%$ e de $\mathrm{P}_{2} \mathrm{O}_{5}-0,04$ a $0,46 \%$ ) (Figura 2, Tabela 1).

São rochas de composição cálcica a cálcio-alcalina, metaluminosas a peraluminosas, com predomínio dos termos peraluminosos (Figura 3) e apresentam razão molecular
A/CNK de 0,87 a 1,33. Possuem grande variação de composição normativa (CIPW), variável de granito a trondhjemito e granodiorito (Figura 4). Possuem grande variação no conteúdo de elementos traço, com teores relativamente baixos a moderados de Y e Nb e alto de Ba, Sr e Rb (Figura 5, Tabela 2).

O conteúdo total de elementos terras raras (ETR) (Tabela 3) varia de baixo a alto $(\Sigma E T R=58,25$ a 339,95) com predomínio de conteúdos moderados. Os padrões de ETR normalizados pelo manto primitivo (Taylor e MacLennan, 1985) apresentam baixos conteúdos de elementos terras raras pesados (ETRP), com distribuição subhorizontal e conteúdos de 1 a 10 vezes os valores do manto primitivo (Figura 6). O padrão de distribuição de elementos terras raras leves (ETRL) é fracionado com enriquecimento moderado a alto, de 1 a 100 vezes o padrão do manto primitivo.

O padrão de distribuição de elementos traço normalizados pelo manto primitivo (Taylor e MacLennan, 1985) revela enriquecimento em $\mathrm{K}$, Rb, Ba e Sr em relação a $\mathrm{Nb}$, ETR, Zr, Ti, $\mathrm{Y}$, mostrando anomalias negativas acentuadas de $\mathrm{Nb}$ e $\mathrm{Ti}$ (Figura 7).

Quimicamente os gnaisses do Arco Magmático de Goiás na região de Arenópolis, Matrinxã, Sancrerlândia e Mara Rosa são metaluminosos de caráter cálcico a cálcio alcalino, com baixos teores de álcalis e altos de $\mathrm{CaO}, \mathrm{MgO}, \mathrm{P}_{2} \mathrm{O}_{5}$ e $\mathrm{Al}_{2} \mathrm{O}_{3}$, mostrando claro enriquecimento em elementos litófilos de íons grandes (LILE) em relação a Nb, Y, Zr e ETR, e baixa abundância de Y e Yb (Pimentel e Fuck, 1991; Rodrigues et al., 1999; Viana et al., 1995). A comparação dos dados geoquímicos das rochas da região de Pontalina com outras regiões do Arco Magmático de Goiás mostra que os gnaisses de Pontalina tendem a ser mais empobrecidos em $\mathrm{Al}_{2} \mathrm{O}_{3}, \mathrm{FeOT}$, $\mathrm{MgO}, \mathrm{CaO}$ e $\mathrm{P}_{2} \mathrm{O}_{5}$ e Sr e enriquecidos em $\mathrm{Ba}, \mathrm{K}_{2} \mathrm{O}$ e ETRL, com valores similares de $\mathrm{Na}_{2} \mathrm{O}, \mathrm{TiO}_{2}$, Y, Nb, Rb, Zr, Ni e ETRP. Os baixos conteúdos em álcalis, o enriquecimento em $\mathrm{Ba}, \mathrm{Sr}, \mathrm{K}$, Rb em relação a Nb, Y, Zr e ETR, e as anomalias negativas de $\mathrm{Nb}$ e Ti, mostram que as rochas apresentam características geoquímicas de magmas gerados em arcos magmáticos.

As idades modelo $\mathrm{T}_{\mathrm{DM}}$ das rochas do Arco Magmático de Goiás variam entre 0,8 a 2,2 Ga, com predomínio de idades entre 0,9 - 1,2 Ga, e valores isotópicos $\varepsilon_{\mathrm{Nd}(\mathrm{T})}$ entre-22 a +5,8, a maioria fracamente negativos $(>-1)$ a positivos. A presença de algumas idades modelo mais velhas são interpretadas como resultado de contaminação por crosta siálica paleoproterozóica (Rodrigues et al., 1999; Pimentel et al., 2000).

As razões isotópicas ${ }^{147} \mathrm{Sm} /{ }^{144} \mathrm{Nd} \mathrm{e}{ }^{143} \mathrm{Nd} /{ }^{147} \mathrm{Nd}$ variam respectivamente entre 0,0881 a 0,1383 e 0,512173 a 0,512600 e, as idades modelo $\mathrm{T}_{\mathrm{DM}}$ obtidas em rochas da região variam entre 0,90 a 1,46 Ga (Figura 8, Tabela 4). Estes dados são semelhantes aos de outras áreas do Arco Magmático de Goiás e mostram que a área estudada se originou na mesma época a partir de mesma fonte ou de fonte semelhante ao do Arco Magmático de Goiás. 

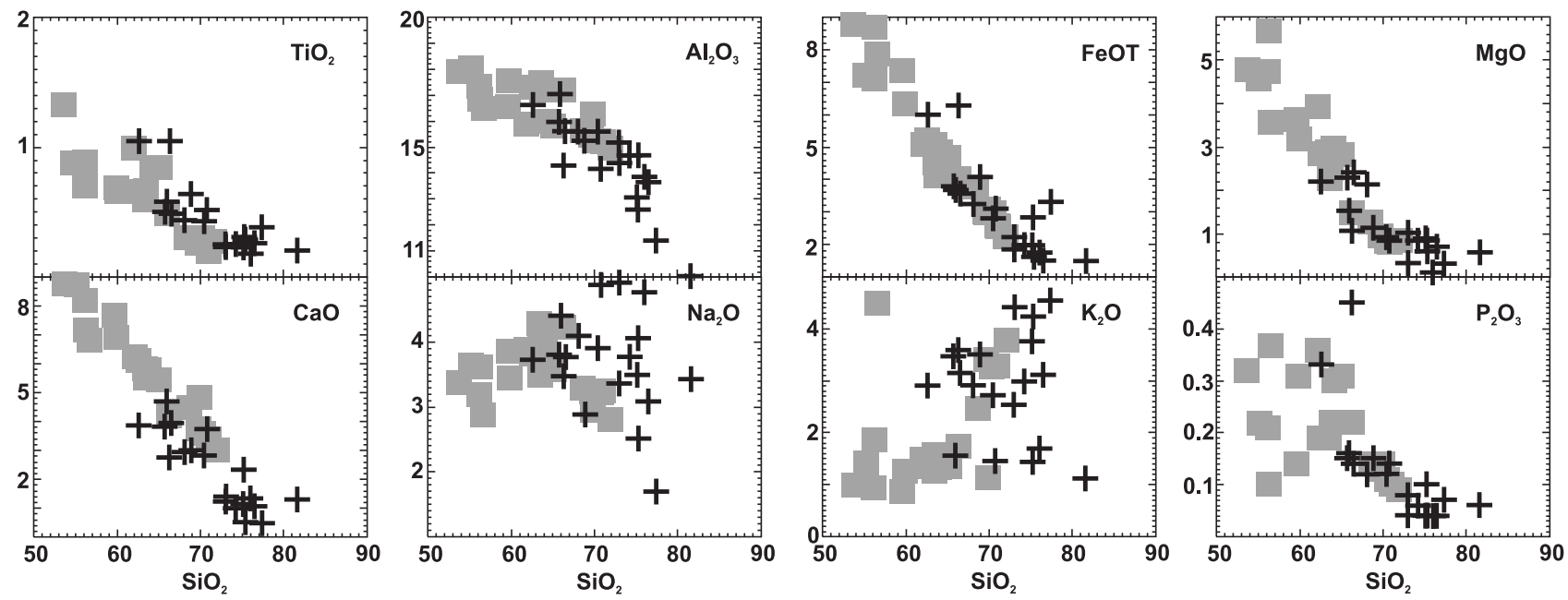

Figura 2. Padrão de distribuição $\mathrm{Ti}_{2} \mathrm{O}_{2}, \mathrm{Al}_{2} \mathrm{O}_{3}, \mathrm{FeOT}, \mathrm{MgO}, \mathrm{CaO}, \mathrm{Na}_{2} \mathrm{O}, \mathrm{K}_{2} \mathrm{O}$ e $\mathrm{P}_{2} \mathrm{O}_{3}$ versus $\mathrm{Si}_{2} \mathrm{O}$. $+\mathbf{t}=$ amostras analisadas. = rochas de outras regiões relacionadas ao Arco Magmático de Goiás (Arenópolis e Mara Rosa, dados de Pimentel e Fuck, 1991; Viana et al., 1995).

Tabela 1. Conteúdo em elementos maiores (em \%) das amostras analisadas.

\begin{tabular}{crrrrrrrrrrrr}
\hline Amostra & $\mathrm{SiO}_{2}$ & $\mathrm{TiO}_{2}$ & $\mathrm{Al}_{2} \mathrm{O}_{3}$ & $\mathrm{Fe}_{2} \mathrm{O}_{3}$ & $\mathrm{MnO}$ & $\mathrm{MgO}$ & $\mathrm{CaO}$ & $\mathrm{Na}_{2} \mathbf{O}$ & $\mathrm{K}_{2} \mathrm{O}_{2}$ & $\mathbf{P}_{2} \mathrm{O}_{5}$ & LOI & Total \\
\hline G5 & 72,40 & 0,23 & 15,03 & 2,04 & 0,05 & 0,32 & 1,39 & 3,34 & 4,37 & 0,04 & 0,78 & 99,99 \\
G6 & 62,28 & 1,04 & 16,52 & 6,64 & 0,07 & 2,19 & 3,81 & 3,71 & 2,90 & 0,33 & 0,88 & 100,36 \\
G7 & 77,27 & 0,38 & 11,37 & 3,66 & 0,07 & 0,30 & 0,47 & 1,69 & 4,52 & 0,07 & 0,85 & 100,64 \\
G8 & 65,99 & 1,05 & 14,20 & 6,95 & 0,11 & 1,06 & 2,74 & 3,45 & 3,54 & 0,45 & 0,68 & 100,22 \\
G11 & 65,96 & 0,58 & 17,02 & 4,09 & 0,03 & 1,52 & 4,69 & 4,40 & 1,54 & 0,16 & 0,71 & 100,69 \\
G12 & 75,85 & 0,18 & 13,82 & 1,95 & 0,03 & 0,12 & 1,33 & 4,75 & 1,68 & 0,04 & 0,30 & 100,05 \\
G13 & 64,41 & 0,49 & 15,63 & 4,10 & 0,07 & 2,23 & 3,74 & 3,72 & 3,38 & 0,15 & 1,16 & 99,08 \\
G13B & 66,08 & 0,49 & 15,48 & 3,93 & 0,05 & 2,39 & 3,92 & 3,75 & 3,11 & 0,14 & 1,05 & 100,37 \\
G17 & 70,28 & 0,43 & 15,55 & 3,11 & 0,03 & 0,90 & 2,79 & 3,88 & 2,70 & 0,12 & 0,74 & 100,53 \\
G18 & 68,50 & 0,64 & 15,16 & 4,49 & 0,11 & 1,11 & 2,94 & 2,86 & 3,47 & 0,15 & 0,57 & 100,01 \\
G23 & 75,35 & 0,23 & 13,09 & 2,21 & 0,05 & 0,88 & 1,15 & 3,50 & 3,75 & 0,04 & 0,69 & 100,96 \\
G25 & 74,69 & 0,31 & 12,48 & 3,13 & 0,04 & 0,83 & 2,32 & 4,02 & 1,40 & 0,10 & 0,73 & 100,05 \\
G26 & 73,21 & 0,25 & 14,47 & 2,17 & 0,04 & 0,84 & 0,96 & 3,71 & 2,94 & 0,06 & 1,48 & 100,11 \\
G27 & 70,44 & 0,52 & 14,07 & 3,44 & 0,08 & 0,85 & 3,70 & 4,85 & 1,43 & 0,14 & 0,76 & 100,28 \\
G28 & 74,32 & 0,29 & 14,45 & 1,75 & 0,04 & 0,57 & 0,50 & 2,46 & 4,15 & 0,04 & 1,40 & 99,99 \\
G29 & 75,61 & 0,26 & 13,47 & 1,63 & 0,03 & 0,68 & 1,06 & 3,05 & 3,07 & 0,04 & 1,15 & 100,07 \\
G33 & 80,74 & 0,20 & 9,92 & 1,64 & 0,04 & 0,56 & 1,30 & 3,39 & 1,11 & 0,06 & 1,84 & 100,79 \\
G34 & 67,98 & 0,44 & 15,56 & 3,59 & 0,04 & 2,13 & 2,94 & 4,08 & 2,89 & 0,12 & 0,72 & 100,50 \\
G37 & 72,72 & 0,25 & 14,32 & 2,45 & 0,06 & 1,03 & 1,23 & 4,89 & 2,52 & 0,08 & 0,70 & 100,25 \\
\hline
\end{tabular}






Figura 3. Gráfico de classificação baseada na relação $\mathrm{Al}_{2} \mathrm{O}_{3}, \mathrm{Na}_{2} \mathrm{O}, \mathrm{K} \mathrm{O}_{\mathrm{O}}$ $\mathrm{CaO} .+=$ amostras analisadas. $\square=$ rochas de outras regiões do Arco Magmático de Goiás (Arenópolis, Iporá, Mara Rosa e Firminópolis, dados de Pimentel e Fuck, 1991; Rodrigues et al., 1999; Viana et al., 1995).



Figura 4. Gráfico de classificação baseado em minerais normativos. $+=$ amostras analisadas. $\square=$ rochas de outras regiões do Arco Magmático de Goiás (Arenópolis, Iporá, Mara Rosa e Firminópolis - dados de Pimentel e Fuck, 1991; Rodrigues et al., 1999; Viana et al., 1995). 


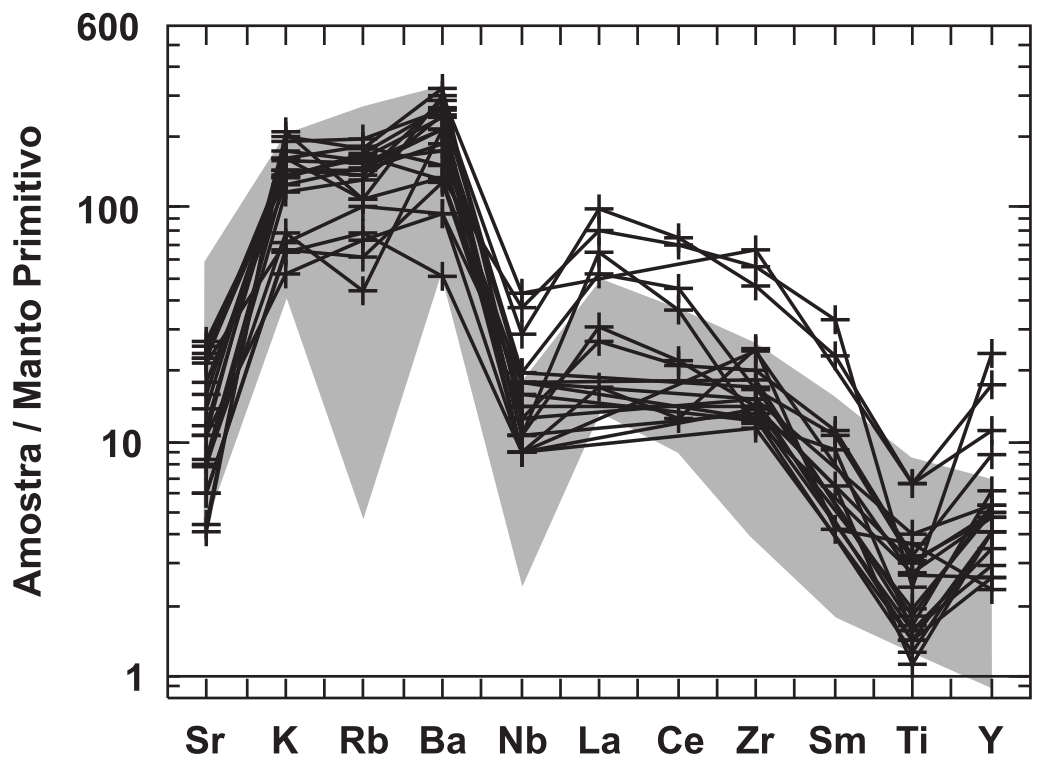

Figura 5. Padrão de distribuição dos elementos traço normalizados pelo manto primitivo (Taylor e MacLennan, 1985). $+=$ amostras analisadas. - rochas de outras regiões do Arco Magmático de Goiás (Arenópolis, Sancrerlândia, Matrinxã e Mara Rosa, dados de Pimentel e Fuck, 1991; Viana et al., 1995).

Tabela 2. Conteúdo em elementos traço (em ppm) das amostras analisadas.

\begin{tabular}{crrrrrrrr}
\hline Amostra & $\mathbf{B a}$ & $\mathbf{R b}$ & $\mathbf{S r}$ & $\mathbf{Y}$ & $\mathbf{Z r}$ & $\mathbf{N b}$ & $\mathbf{C u}$ & $\mathbf{N i}$ \\
\hline G5 & 1629 & 98 & 1910 & 14 & 125 & 7 & 3 & 4 \\
G6 & 1369 & 94 & 453 & 38 & 385 & 16 & 2 & 20 \\
G7 & 692 & 60 & 73 & 81 & 467 & 21 & 12 & 5 \\
G8 & 1542 & 60 & 281 & 60 & 553 & 24 & 7 & 6 \\
G11 & 476 & 55 & 382 & 8 & 208 & 5 & 69 & 12 \\
G12 & 1102 & 24 & 143 & 14 & 117 & 6 & 6 & 8 \\
G13 & 1100 & 86 & 420 & 16 & 138 & 11 & 15 & 37 \\
G13B & 954 & 80 & 408 & 17 & 118 & 8 & 19 & 29 \\
G17 & 1105 & 81 & 316 & 9 & 203 & 5 & 10 & 4 \\
G18 & 773 & 100 & 209 & 18 & 125 & 10 & 11 & 7 \\
G23 & 889 & 87 & 246 & 9 & 94 & 5 & 1 & 5 \\
G25 & 260 & 43 & 107 & 17 & 115 & 5 & 18 & 4 \\
G26 & 1247 & 90 & 148 & 12 & 109 & 6 & 1 & 4 \\
G27 & 653 & 34 & 108 & 30 & 166 & 7 & 1 & 4 \\
G28 & 1317 & 107 & 79 & 18 & 141 & 11 & 2 & 5 \\
G29 & 1479 & 76 & 403 & 21 & 151 & 10 & 7 & 4 \\
G33 & 479 & 40 & 190 & 14 & 105 & 10 & 14 & 6 \\
G34 & 675 & 91 & 481 & 16 & 101 & 9 & 7 & 23 \\
G37 & 1283 & 72 & 138 & 10 & 99 & 6 & 2 & 3 \\
\hline
\end{tabular}


Tabela 3. Conteúdo em elementos terras raras (em ppm) das amostras analisadas.

\begin{tabular}{crrrrrrrrrrrrr}
\hline Amostra & La & Ce & Nd & Sm & Eu & Gd & Dy & Er & Yb & Lu & $(\mathrm{La} / \mathrm{Eu})_{\mathbf{N}}$ & $(\mathrm{Gd} / \mathrm{Lu})_{\mathbf{N}}$ & $(\mathrm{La} / \mathrm{Lu})_{\mathbf{N}}$ \\
\hline G5 & 45,00 & 84,00 & 30,00 & 4,80 & 1,20 & 3,60 & 2,60 & 1,60 & 1,50 & 0,30 & 13,23 & 1,43 & 25,62 \\
G6 & 54,80 & 107,00 & 45,10 & 8,20 & 1,80 & 7,50 & 6,10 & 3,50 & 2,70 & 0,40 & 11,13 & 1,77 & 18,57 \\
G7 & 43,50 & 100,00 & 47,80 & 11,50 & 1,70 & 12,00 & 12,20 & 8,10 & 8,10 & 1,30 & 9,31 & 0,92 & 4,73 \\
G11 & 9,40 & 18,00 & 7,20 & 1,50 & 0,80 & 1,20 & 1,60 & 1,20 & 0,90 & 0,20 & 4,31 & 0,76 & 8,37 \\
G12 & 17,00 & 32,20 & 11,60 & 2,30 & 0,60 & 2,00 & 1,90 & 1,20 & 1,30 & 0,20 & 10,08 & 0,92 & 11,00 \\
G13 & 28,80 & 64,30 & 21,20 & 3,70 & 1,00 & 3,00 & 2,30 & 1,40 & 1,40 & 0,20 & 10,01 & 1,40 & 19,52 \\
G27 & 14,90 & 30,30 & 15,30 & 3,80 & 1,10 & 3,80 & 4,10 & 2,80 & 2,70 & 0,40 & 4,73 & 0,89 & 4,93 \\
G37 & 35,20 & 52,20 & 19,20 & 3,20 & 0,90 & 2,30 & 1,60 & 0,90 & 0,90 & 0,20 & 14,30 & 1,43 & 31,31 \\
\hline
\end{tabular}

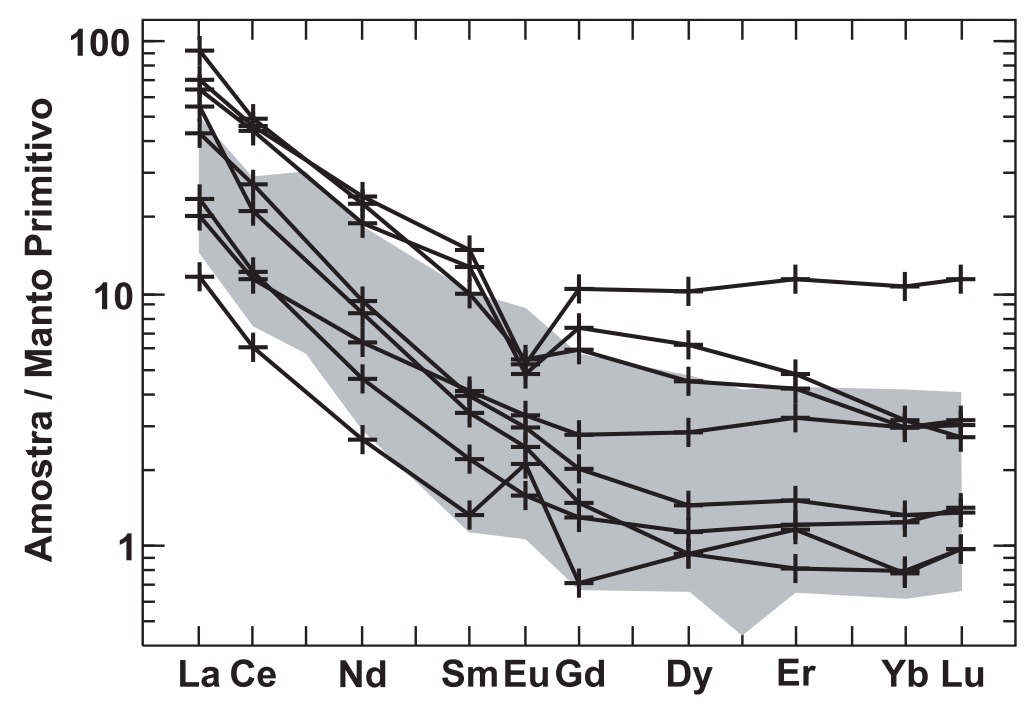

Figura 6. Padrão de distribuição de ETR normalizados ao manto primitivo (Taylor e MacLennan, 1985). $+=$ amostras analisadas. = rochas de outras regiões do Arco Magmático de Goiás (Arenópolis, Sancrerlândia, Matrinxã e Mara Rosa, dados de Pimentel e Fuck, 1991; Viana et al., 1995).
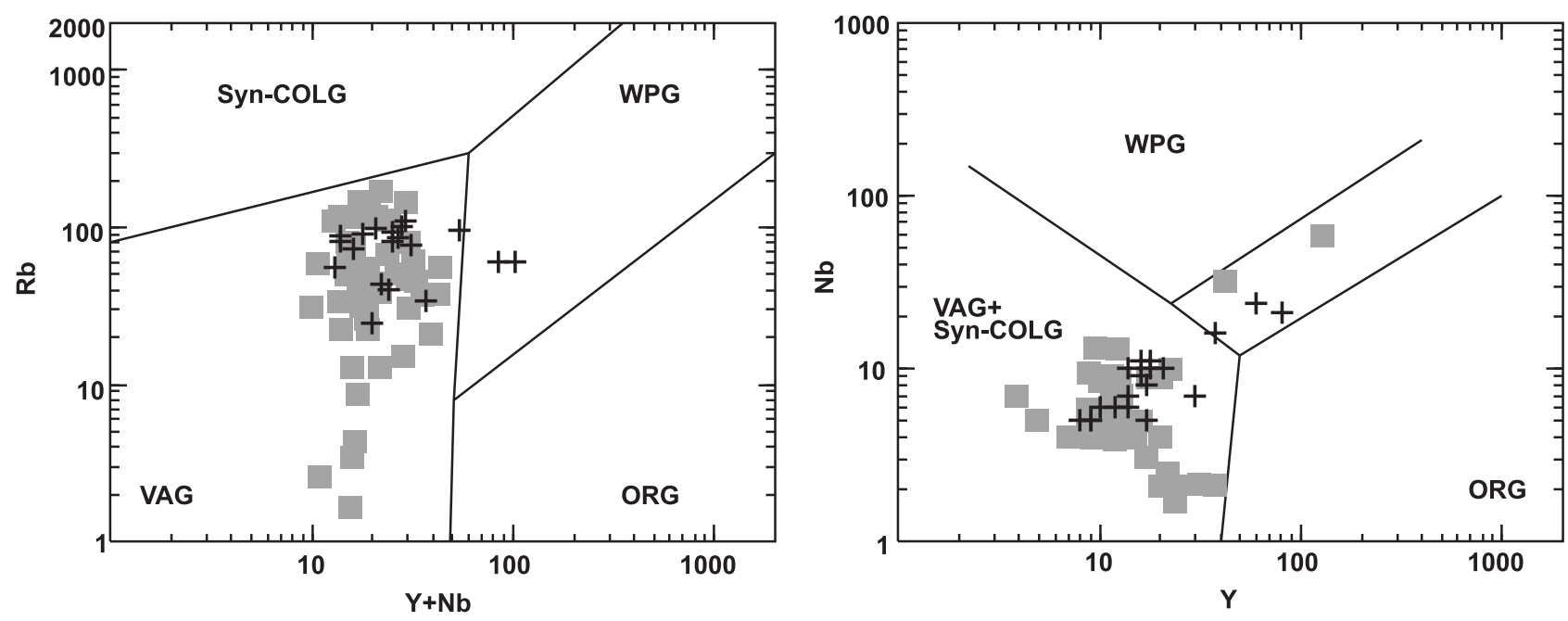

Figura 7. Gráficos discriminantes de ambientes tectônicos (Pearce et al., 1984). $+=$ amostras analisadas. $\square=$ rochas de outras regiões do Arco Magmático de Goiás (Arenópolis, Sancrerlândia, Iporá, Firminópolis, Matrinxã e Mara Rosa, dados de Pimentel e Fuck, 1991; Rodrigues et al., 1999; Viana et al., 1995). 

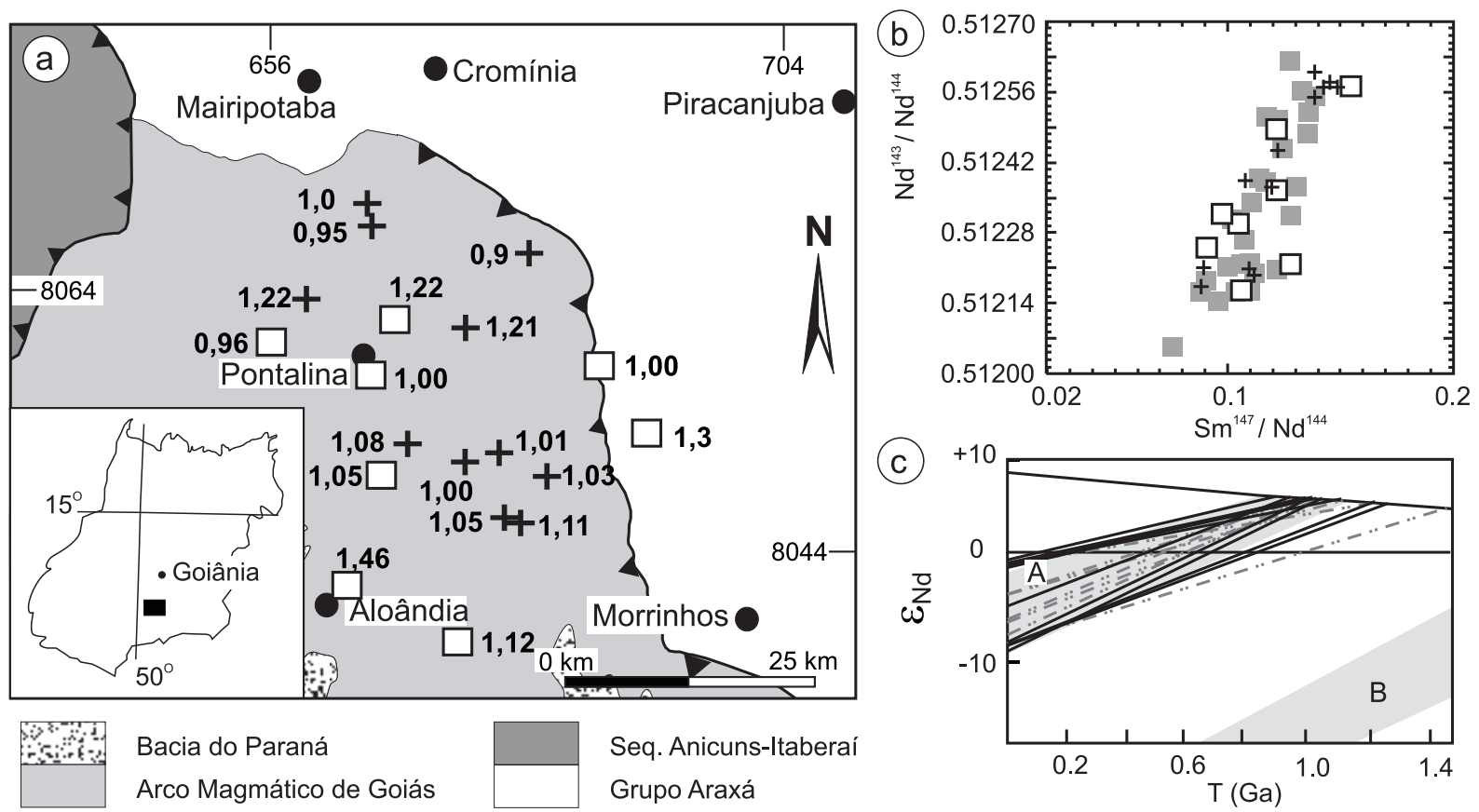

Figura 8. a. Mapa geológico esquemático simplificado da região de Pontalina com a localização das idades modelo obtidas. b. Composição isotópica (razões ${ }^{147} \mathrm{Sm} /{ }^{144} \mathrm{Nd}$ e ${ }^{143} \mathrm{Nd} /{ }^{147} \mathrm{Nd}$ ) das amostras da região de Pontalina. c. Variação dos valores de $\varepsilon_{\mathrm{Nd}}$ no tempo geológico de gnaisses da área de estudo ( $>$ = amostras analisadas; $-\cdot \cdot-\cdot \cdot-=$ dados de Pimentel et al. (2000)). $\mathbf{A}=$ composição isotópica de rochas de outras regiões do Arco Magmático de Goiás. $\mathbf{B}=$ composição isotópica de gnaisses arqueanos de Goiás. $+=$ amostras analisadas. $\square=$ dados de Pimentel et al. (2000). = rochas de outras regiões do Arco Magmático de Goiás.

Tabela 4. Dados $\mathrm{Sm} / \mathrm{Nd}$ e idades modelo de gnaisses e rochas metamáficas da região de Pontalina. * = valores de Pimentel et al. (2000); GN = gnaisse; $\mathbf{A N F}=$ anfibolito; $\mathbf{M V}=$ metavulcânica.

\begin{tabular}{ccrrrrrr}
\hline Amostra & & $\mathbf{S m}$ & $\mathbf{N d}$ & ${ }^{147} \mathbf{S m} /{ }^{144} \mathbf{N d}$ & ${ }^{143} \mathbf{N d} /{ }^{144} \mathbf{N d}( \pm \mathbf{2 S E})$ & $\mathbf{G a}$ & $\mathcal{E}_{(\mathbf{0})}$ \\
\hline G7 & GN & 12,163 & 53,166 & 0,1383 & $0,512600(10)$ & 0,90 & $-0,74$ \\
G9 & MV & 12,079 & 67,700 & 0,1079 & $0,512383(19)$ & 0,95 & $-4,97$ \\
G11 & GN & 1,635 & 9,010 & 0,1097 & $0,512209(07)$ & 1,22 & $-8,37$ \\
G11B & GN & 1,563 & 8,475 & 0,1115 & $0,512197(06)$ & 1,26 & $-8,60$ \\
G24 & MV & 2,524 & 10,260 & 0,1487 & $0,512569(07)$ & 1,11 & $-1,35$ \\
G25 & GN & 3,322 & 22,786 & 0,0881 & $0,512173(08)$ & 1,06 & $-9,07$ \\
G25B & GN & 3,247 & 21,895 & 0,0896 & $0,512210(05)$ & 1,03 & $-8,35$ \\
G30 & MV & 5,668 & 24,054 & 0,1424 & $0,512570(69)$ & 1,01 & $-1,33$ \\
G41 & GN & 4,001 & 17,467 & 0,1385 & $0,512549(06)$ & 1,00 & $-1,74$ \\
G42 & GN & 3,122 & 13,013 & 0,1450 & $0,512579(13)$ & 1,03 & $-1,15$ \\
A3 & ANF & 7,500 & 37,000 & 0,1225 & $0,512445(06)$ & 1,00 & $-3,76$ \\
A10 & ANF & 5,328 & 26,961 & 0,1195 & $0,512372(21)$ & 1,09 & $-5,19$ \\
PONT1* & & 7,343 & 45,090 & 0,0980 & $0,512317(23)$ & 0,96 & $-6,26$ \\
PONT2* & & 8,403 & 41,540 & 0,1220 & $0,512438(07)$ & 1,01 & $-3,90$ \\
PONT3* & & 3,807 & 21,960 & 0,1050 & $0,512296(45)$ & 1,05 & $-6,67$ \\
PONT4B & ANF & 3,630 & 24,080 & 0,0910 & $0,512249(21)$ & 0,99 & $-7,59$ \\
PONT5* & & 5,010 & 19,500 & 0,1550 & $0,512570(05)$ & 1,23 & $-1,33$ \\
PONT6* & & 7,014 & 39,920 & 0,1060 & $0,512164(12)$ & 1,24 & $-9,25$ \\
ALO1* & & 5,891 & 27,700 & 0,1280 & $0,512219(20)$ & 1,46 & $-8,17$ \\
ALO2* & & 3,771 & 18,680 & 0,1220 & $0,512365(12)$ & 1,13 & $-5,33$ \\
\hline
\end{tabular}




\section{CONCLUSÕES}

A interpretação dos dados evidencia que os gnaisses de Pontalina pouco diferem dos de área-tipo do Arco Magmático de Goiás situados em Arenópolis, Mara Rosa, Sancrerlândia, Iporá e Firminópolis, mas são em parte mais diferenciados. Os da região de Pontalina tendem a ser mais pobres em $\mathrm{Al}_{2} \mathrm{O}_{3}$, FeOT, MgO, CaO, $\mathrm{P}_{2} \mathrm{O}_{5}$ e $\mathrm{Sr}$, mais ricos em $\mathrm{Ba}, \mathrm{K}_{2} \mathrm{O}$ e ETRL, $\mathrm{e}$ exibem valores semelhantes de $\mathrm{Na}_{2} \mathrm{O}, \mathrm{TiO}_{2}, \mathrm{Y}, \mathrm{Nb}, \mathrm{Rb}, \mathrm{Zr}$, Ni e ETRP. Estes dados geoquímicos e a pronunciada anomalia negativa de $\mathrm{Nb}$ e Ti sugerem que as rochas da região se formaram em ambientes de arco de ilha. As características isotópicas Sm - Nd dos gnaisses e de rochas metamáficas da região são semelhantes as das rochas do Arco Magmático de Goiás, mostrando que a mesma faz parte da mesma unidade geotectônica.

\section{AGRADECIMENTOS}

À FAPESP (processos 2001-10034-2 e 2001/08456-6) e ao CNPq (processos 140418/02-4 e 303267/2002-0).

\section{REFERÊNCIAS BIBLIOGRÁFICAS}

ARAÚJO, V. A.; GODOI, P. V. B.; ARAUJO, H. O. DE; MORETON, E. S.; SILVA, L. C.; SA, M.A. D.; MARTINS, A., M. DE; MATOS, E. G.; ANDRADE, S. H. S. DE; SALES, R.; BERBERT, C. O.; OLIVATTI, O. Projeto Pontalina Fase I. Goiânia: SURGEO/DNPM/CPRM, 1980. v. 1.

FUCK, R. A.; PIMENTEL, M. M.; SILVA, L. J. H. D. Compartimentação tectônica na porção oriental da Província Tocantins. In: CONGRESSOBRASILEIRODEGEOLOGIA, 38., 1994, Camboriu. Boletim resumos expandidos... Camboriu: Sociedade Brasileira de Geologia, 1994. p. 215-216. v. 1.

HACKSPACHER, P. C.; TRINDADE, I. R.; FETTER, A. H.; DANTAS, E. L.; SANTOS, B. L. C. Desenvolvimento das sistemáticas isotópicas U-Pb e $\mathrm{Sm} / \mathrm{Nd}$ aplicadas em cronologia no laboratório de Geoquímica Isotópica da UNESP Rio Claro. In: SIMPÓSIO 40 ANOS DE GEOCRONOLOGIA NO BRASIL, 2004, São Paulo. Boletim de resumos... São Paulo: CEPGeo-USP, 2004. p. 25.

LACERDA FILHO, J. V. de. Geologia e esboço tectônico da folha Goiânia - SE.22-X. In: SIMPÓSIO DE GEOLOGIA DO CENTRO-OESTE, 5., 1995, Goiânia. Anais... Goiânia: Sociedade Brasileira de Geologia - Núcleos Centro-Oeste e Brasília, 1995. p. 160-165. $1 \mathrm{v}$.

LAUX, J. H.; PIMENTEL, M. M.; DANTAS, E. L.; ARMSTRONG R.; JUNGES, S. L. Two neoproterozoic crustal accretion events in the Brasília belt, central Brazil. Journal of
South American Earth Sciences, v. 18, n.2, p. 183-198, 2005.

NAVARRO, G R. B.; ZANARDO,A.; GALEMBECK, T. M. B.; ROCHA, M. M. C. Idades Modelo dos Gnaisses da Região de Pontalina Goiás. In: CONGRESSO BRASILEIRO DE GEOLOGIA, 42., 1994, Araxá. Anais.... Araxá: Sociedade Brasileira de Geologia - Núcleo Minas Gerais, 2004. (1 CD-ROM).

NAVARRO, G. R. B.; ZANARDO,A.; SIMÕES, L. S.A. Litogeoquímica de rochas metamáficas na região de Pontalina no sul do Estado de Goiás. In: SIMPÓSIO SOBRE O CRATON DO SÃO FRANCISCO, 3., 2005, Salvador. Anais... Salvador: Sociedade Brasileira de Geologia - Núcleo Bahia, 2005. p 102-105.

PEARCE, J.A.; HARRIS, N.B. W.; TINDLE,A.G Trace element discrimination diagrams for the tectonic interpretation of granitic rocks. Journal Petrology, v. 25, n. 4, p. 956-983, 1984.

PIMENTEL, M. M.; FUCK, R. A. Origin of orthogneiss and metavolcanic rock units in western Goiás: Neoproterozoic crustal accretion. Geochimica Brasiliensis., v. 5, n.1/2, p. 133-152, 1991.

PIMENTEL, M. M.; FUCK, R. A.; GIOIA, S. M. C. L. The neoproterozoic Goiás Magmatic Arc, central Brazil: A review and new Sm-Nd isotopic data. Revista Brasileira de Geociências, v. 30, n. 2, p. 35-39, 2000.

PIMENTEL, M. M.; JOST, H.; FUCK, R. A. O embasamento da Faixa Brasília e o arco Magmático de Goiás. In: MANTESSONETO, V., BARTORELLI,A., CARNEIRO, C. DAL RÉ;BRITONEVES, B. B. de (Coord.). Geologia do Continente Sul-Americano: evolução da obra de Fernando Flávio Marques de Almeida. São Paulo: Beca, 2004. p. 355-368.

RICHARD, L. R. MINPET-Mineralogical and petrological data processing system. Minpet for Windows, version 2.02. 1995.

RODRIGUES, J. B.; GIOIA, S. M. C. L.; PIMENTEL, M. M. Geocronologia e geoquímica de ortognaisses da região entre Iporá e Firminópolis: implicações para a evolução do Arco Magmático de Goiás. Revista Brasileira de Geociências, v. 29, n. 2, p. 207-216, 1999.

TAYLOR, S. R.; MACLENNAN, S. M. The continental crust: its composition and evolution. Oxford: Blackmell, 1985. 312 p.

VIANA,M.G;PIMENTEL,M.M.;WHITEHOUSE,M.J.;FUCK, R.A.; MACHADO, N. O Arco Magmático de Mara Rosa, Goiás: geoquímica e geocronologia e suas implicações regionais. $R e$ vista Brasileira de Geociências, v. 25, n. 2, p. 111-123, 1995. 